\title{
Highly Efficient Synthesis of $\mathrm{CF}_{3}$-Containing 7-Aminoquinolines From Cyclocondensation Reaction of Trifluoroacetyl Enamine Precursors
}

\author{
Rosália Andrighetto (PG), Helio G. Bonacorso (PQ), Jussara Navarini (PG), Nícolas \\ Krüger (IC), Marcos A. P. Martins (PQ), Nilo Zanatta (PQ)
}

Núcleo de Química de Heterociclos (NUQUIMHE), Departamento de Química, Universidade Federal de Santa Maria, 97105-900 - Santa Maria, RS. ${ }^{*}$-mail heliogb@base.ufsm.br (H.G. Bonacorso)

Keywords: Quinolines, Trifluoromethylated ketones, Cyclocondensation reactions

\section{INTRODUCTION}

The quinoline ring system occurs in numerous natural products, especially in alkaloids, and presents a wide spectrum of physiological activities. ${ }^{1}$ Much attention is still being given to the synthesis of quinoline derivatives because of their industrial applications and pharmacological properties. $^{2}$ Trifluoromethyl substituted quinolines are the subject of growing interest because of their medicinal importance, particularly as antimalarial agents (e.g., mefloquine and halofantrine). ${ }^{3}$ Since the classical antimalarial molecules are encountering increased drug resistance, considerable efforts have been directed toward the synthesis of new fluorinated quinolines that can provide improved anti-parasitic activity. ${ }^{4}$ The purpose of this work is to report the results of a chemical behavior study of the reactions of ketones 1 with 2,6-diaminotoluene (2,6-DAT).

\section{RESULTS AND DISCUSSION}

Trifluoromethylated ketones 1a-f when added to 2,6DAT at a molar ration of $1: 1$, in pure methanol as solvent at $0{ }^{\circ} \mathrm{C}$ for $2 \mathrm{~h}$, furnished a new series of six enaminone intermediates $2 \mathrm{a}-\mathrm{f}$ in $46-70 \%$ yields. In addition, we found that enones $\mathbf{1 g - i}$ under the same or optimized reaction conditions described above allowed us to directly obtain 7 -aminoquinolines $\mathbf{3 g}$-i $(21-36 \%)$ instead of the corresponding enaminones $\mathbf{2 g - i}$. In a second reaction step, the acyclic enaminones $\mathbf{2 a - f}$ were subjected to reactions carried out in the presence of a strongly acidic medium (polyphosphoric acid, PPA). The cyclization of 2 a-f showed that the best results were at $90{ }^{\circ} \mathrm{C}$ for $6 \mathrm{~h}$, affording the corresponding new series of 7aminoquinolines $\mathbf{3 b - f}$ in $86-93 \%$ yields (Scheme 1 ). It is not surprising that only traces of compound $\mathbf{3 a}$ were obtained since enaminone derivatives of enone 1a present a different chemical behavior from other enones. ${ }^{5}$

\section{CONCLUSION}

We described a simple, highly efficient and inexpensive route to prepare trifluoromethyl substituted aminoquinolines through cyclization of a variety of enaminones. Our strategy was effective, rapid and allowed adequate diversity of substituents in the construction of the quinoline ring system.

\section{ACKNOWLEDGEMENTS}

CNPq-CAPES-FATEC

\section{REFERENCES}

${ }^{1}$ Michael, J. P. Nat. Prod. Rep. 1997, 14, 11.

${ }^{2}$ Kouznetsov, V. V.; Méndez, L. Y. V.; Gómez, C. M. M. Curr. Org. Chem. 2005, 9, 141.

${ }^{3}$ Wiesner, J.; Ortmann, R.; Jomaa, H.; Schlitzer, M. Angew. Chem., Int. Ed. 2003, 43, 5274.

${ }^{4}$ Ismail F. M. J. Fluorine Chem. 2002, 118, 27.

5 a) Bonacorso, H. G.; Duarte, S. H. G.; Zanatta, N.; Martins, M. A. P. Synthesis 2002, 1037. b) Bonacorso, H. G.; Andrighetto, R.; Zanatta, N.; Martins, M. A. P. Tetrahedron Lett. 2010, 51, 3752.

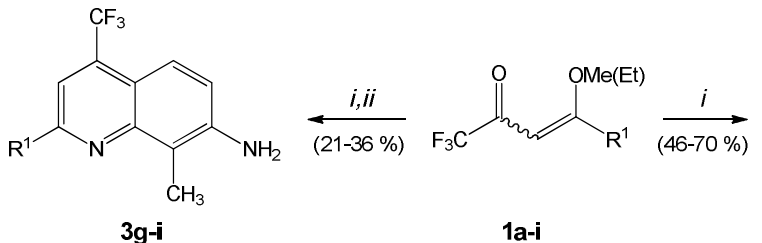<smiles>[R]/C(=C/C(=O)C(F)(F)F)Nc1cccc(N)c1C</smiles>

2a-f<smiles>[R]c1cc(C(F)(F)F)c2ccc(N)c(C)c2n1</smiles>

3b-f

$$
\begin{array}{c|ccccccccc}
1-3 & \text { a } & \text { b } & \text { c } & \text { d } & \text { e } & \text { f } & \text { g } & \text { h } & \text { i }
\end{array}
$$

(i) = 2,6-Diaminotoluene (1.0 equiv.), $\mathrm{MeOH}, 0^{\circ} \mathrm{C}, 2 \mathrm{~h}$; (ii) $=\mathrm{MeOH}$, reflux, $24 \mathrm{~h}$; (iii) $=\mathrm{PPA}, 90^{\circ} \mathrm{C}, 6 \mathrm{~h}$.

Scheme 1. Synthesis of trifluoromethyl substituted 7-aminoquinolines. 